\section{Digging holes and weaving tapestries: two approaches to the clinical encounter}

\author{
John Launer
}

Much of medicine consists of getting to the bottom of things. Here is a typical example. A man in his sixties walks into an emergency department complaining of brief loss of consciousness (myself, as it happens, exactly 3 years ago). Within a few minutes, the emergency medicine consultant gets to the bottom of things: an ECG shows complete heart block and so a few days later the patient is fitted with a pacemaker. There are of course further questions to be explored, such as what the underlying pathology was (ischaemic heart disease) and what the antecedents were (a strong family history.) One can even dig further down, discovering more at each level (like lipid disorders and genes). Each of these is a distinct thing, and each has a bottom. It is a very rewarding activity, and one that scientific medicine, and investigative medicine in particular, are especially good at.

Sometimes, however, people come to see us with problems that do not seem either to be things or to have bottoms. Every doctor is familiar with patients who present with a vague and variable combination of fatigue, weakness, headaches, palpitations, muscular aches, abdominal pains, backache and light-headedness. Usually, we feel obliged to dig down below each of these symptoms in a conventional medical way, knowing the whole time that we are most unlikely to find anything of significance, except perhaps one slightly abnormal blood test that later turns out to be a time-consuming and expensive red herring. Quite often, the patient will urge us on in this fruitless search by themselves insisting "We need to get to the bottom of this thing, doctor." So we carry on digging, even when we know in our heart of hearts that concepts like things or bottoms are not really of any use in these circumstances. In the end, we will probably end up assigning the person's constellation of problems to a category like 'psychosomatic' or 'medically unexplained symptoms' rather than shifting our mode of thinking, as I believe

Associate Editor, Postgraduate Medical Journal, London, UK

Correspondence to Dr John Launer, London, UK; johnlauner@aol.com we should, to a different orientation altogether: not vertical but horizontal.

For many years, I have used a slide in my teaching that shows two contrasting pictures - a man in a hat digging a hole, and a beautiful French tapestry. (It is 'The lady and the unicorn' woven from wool and silk around the year 1500, and on display at the Musée de Cluny in Paris.) (see figure 1) I know of no better way to convey the difference between the approach we habitually take to problemsolving as doctors, and the entirely different one that is needed whenever this does not work. Digging a hole requires intense effort and single-mindedness. Weaving a tapestry involves immense delicacy and careful collaboration. One activity is practical, the other is aesthetic. At least in western cultures, digging holes has largely been a task for men, while tapestry-making has almost exclusively been the province of women. Doctors, I would suggest, need to be able to do both, and to realise when to move from one to the other.

\section{MAIN CHARACTERISTICS}

We all know the essentials of digging a hole, medically speaking, because we do it all the time, so let me delineate instead what I regard as the three main characteristics of weaving a tapestry in the clinical encounter. The first is what the poet John Keats famously called 'Negative Capability." He defined this as "capable of being in uncertainties, mysteries, doubts, without any irritable reaching after fact and reason." I know many doctors who have acquired such a capability through personal and professional experience,

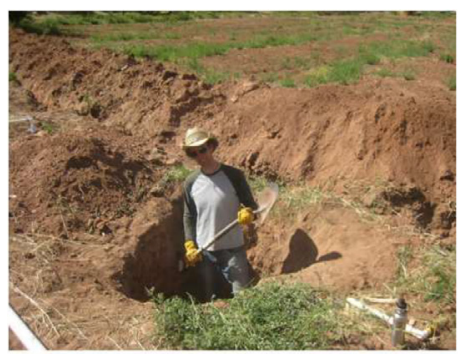

Figure 1 Digging a hole and weaving a tapestry. but feel slightly ashamed of it, as if they are committing a sin by suspending their belief in the received truths of their education. The next characteristic is one I would call 'courteous curiosity.' This is an ability to ask in detail about someone's subjective experience and to try and understand it through the patient's own words, without judging or categorising anything, or reframing it in a more official way,. The final characteristic is unrelenting positivity: holding on to belief that every narrative has its own momentum; if it is explored with respect and kindness, and allowed enough freedom, it will reveal a potential to surprise both doctor and patient alike. Taken together, these characteristics constitute a polite but creative way of distracting the patient from a repetitive lament, but without directly saying so or crassly putting them straight into the box labelled 'psychosomatic'.

\section{VALIDATING PEOPLE}

I suspect that many clinicians will recognise the attitude I am talking about, but may never have seen it named, or read an account of it being applied. One of the best accounts I know has been offered by clinical psychologists Angela Griffin and Deborah Christie. ${ }^{2}$ It is based on their work on an in-patient ward with adolescents who have a range of severe and debilitating symptoms, all conventionally described as 'medically unexplained' or 'psychosomatic.' Their results are encouraging.

Griffin and Christie describe an essential element of their approach as 'problemfree talk': finding out about the person rather than the problem. Drawing on the work of the Australian therapist Michael White, ${ }^{3}$ they validate people by exploring life before the problem began, and helping them to recall moments since then, however short, when the problem was kept in its place. They use language that continually implies that the problem is external and negotiable, rather than something fixed that needs a professional

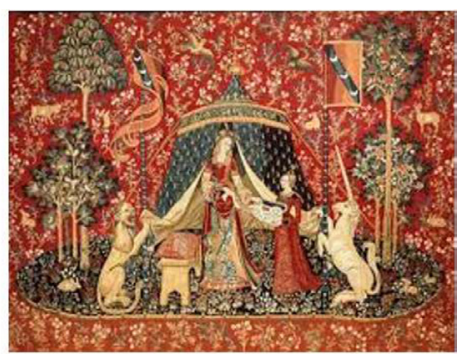




\section{On reflection}

to sort out. For example, they inquire how patients might visualise their problems, and get answers like 'a small green imp', 'a hard red ball' or 'a big black cloud'. They tend not to dwell on negativity, but are strong on congratulating patients on any amelioration of their symptoms. They do not use the metaphor of weaving a tapestry, but their description of their approach fits with it nicely:

This is not 'Pollyanna' therapy. We know that people's problems are real and must be taken seriously. We listen carefully to a problem if someone wants to tell us. However, our aim is to not give the problem too much oxygen. We will validate and acknowledge the difficulties, without actively probing and enquiring about them once they have been aired... Asking questions that invite young people to find their own solutions means that we don't need to know any answers, we just need to ask questions.
Few clinicians will have the time and psychological skills that Griffin and Christie possess, but then few of us work in such challenging settings, and with so refractory a group of patients. The principles of what they do can be still applied, either as an adjunct to hole-digging, or as a more effective substitute for doing so. There are many situations in medicine where we go on digging simply because it is what we were trained to do, and always do. It is at times like these that we need to exercise negative capability, courteous curiosity, positivity, and creative distraction, and start to weave a tapestry instead.

Twitter John Launer @JohnLauner

Funding The authors have not declared a specific grant for this research from any funding agency in the public, commercial or not-for-profit sectors.

Competing interests None declared.

Patient consent for publication Not required.
Provenance and peer review Not commissioned; internally peer reviewed.

(c) Author(s) (or their employer(s)) 2020. No commercial re-use. See rights and permissions. Published by BMJ.

\section{Check for updates}

To cite Launer J. Postgrad Med J 2020;96:307-308.

Postgrad Med J 2020;96:307-308.

doi:10.1136/postgradmedj-2020-137764

\section{REFERENCES}

1 Keats J. Letters of John Keats, to his family and friends. London: Macmillan, 1891: 48.

2 Griffin A, Christie D. Taking the psycho out of psychosomatic: using systemic approaches in a paediatric setting for the treatment of adolescents with unexplained physical symptoms. Clin Child Psychol Psychiatry 2008;13:531-42.

3 White M, Epston D. Narrative means to therapeutic ends. New York: Norton, 1990. 